\title{
CARCINOMA INDIFERENCIADO METASTÁTICO EM BOVINO LEITEIRO: RELATO DE CASO
}

\author{
Dairy cattle undifferentiated metastatic carcinoma: a case report
}

\begin{abstract}
Fernanda Dariva ${ }^{1}$, Paola Carla Valduga ${ }^{2}$, Ana Luiza Lira ${ }^{3}$, Rosicler Colet $^{4}$, Juliana Franciele Ruzycki $^{2}$, Diorges Henrique Setim ${ }^{5}$, Mauro Antônio de Almeida ${ }^{5}$, Geciane Toniazzo Backes ${ }^{5}$, Daniela dos Santos de Oliveira ${ }^{5}$
\end{abstract}

\begin{abstract}
${ }^{1}$ Graduanda do Curso de Medicina Veterinária da URI Erechim.E-mail: fe.dariva@hotmail.com
${ }^{2}$ Graduanda do Curso de Medicina Veterinária da URI Erechim.

${ }^{3}$ Graduada do Curso de Medicina Veterinária do Instituto de Desenvolvimento Educacional do Alto Uruguai. Mestranda do Curso de Engenharia de Alimentos da URI Erechim. E-mail: analuizalira8@ gmail.com

${ }^{4}$ Pós-doutoranda do Curso de Engenharia de Alimentos da URI Erechim. E-mail: rosicler.colet@yahoo. com.br

${ }^{5}$ Professor do Curso de Medicina Veterinária da URI Erechim.
\end{abstract}

Data do recebimento: 22/04/2021 - Data do aceite: 08/07/2021

RESUMO: O carcinoma, tumor maligno, pode conter arranjos celulares em ninhos, cordões e/ou ilhas de células epiteliais, sendo invasivo, com elevado potencial metastático. As neoplasias podem ser oriundas de alterações genéticas hereditárias ou até mesmo de causas químicas, físicas (radiação) ou infecciosas, e se farão presentes em todas as células do organismo. Sendo geralmente diagnosticadas no post mortem, o aparecimento de tumores em bovinos não é considerado um achado corriqueiro, pois acredita-se que a maioria deles não atinge uma idade suficiente para predispor ao desenvolvimento de neoplasias. O objetivo do trabalho foi relatar um achado de necropsia em uma vaca da raça Holandesa preta e branca, com 7 anos de idade e 200 dias de lactação. Foi realizada a anamnese do animal na propriedade rural e após relatos do produtor procedeu-se avaliação clínica, realizando-se a palpação retal, que com prognóstico desfavorável, definiu-se a eutanásia do animal. Foi realizada necropsia e foram coletados fragmentos da glândula mamária, linfonodos mesentéricos, ilíacos e dos rins. O diagnóstico de carcinoma indiferenciado metastático foi confirmado através de exame macroscópico e microscópico. Estas neoplasias são uma das principais causas de descarte precoce de bovinos. 
Palavras-chave: Tumor. Glândula mamária. Linfonodos. Rins.

\begin{abstract}
Carcinoma, a malignant tumor, may contain cellular arrangements in nests, cords and/ or islands of epithelial cells, and it can be considered invasive with high metastatic potential. Neoplasms can originate from inherited genetic alterations or even from chemical, physical (radiation) or infectious causes, which will be present in all cells of the organism. Tumors are generally post-mortem diagnosed, and their appearance in cattle is not considered a common finding, as it is believed that most of them are not old enough to predispose to the development of neoplasms. The aim of this work was to report a necropsy finding in a 7-year-old black and white Holstein cow with 200 days of lactation. The Anamnesis of the animal was carried out in the rural property and, after reports from the producer, a clinical evaluation and rectal palpation were performed, which with an unfavorable prognosis, defined the euthanasia of the animal. At the necropsy, fragments of the mammary gland, mesenteric, iliac lymph nodes and kidneys were collected. The diagnosis of undifferentiated metastatic carcinoma was confirmed through macroscopic and microscopic exams. These neoplasms are one of the main causes of cattle early disposal.
\end{abstract}

Keywords: Tumor. Mammary gland. Lymph nodes. Kidneys

\section{Introdução}

As neoplasias em bovinos apresentam ocorrência esporádica e não são descritas com frequência na literatura brasileira, sendo grande parte das informações relatadas por casos específicos de neoplasias detectadas em exame post, e esporadicamente, ante mortem (RAMOS et al., 2008, CARVALHO et al., 2014, TESSELE, 2016). Segundo Martz (2020), os relatos de tumores em bovinos são considerados raros se comparados a outros animais domésticos, pois a maioria dos bovinos não atinge uma idade suficiente para manifestar clinicamente os tumores.

Para Cullen et al. (2002) a classificação de tumores em animais domésticos pode estar relacionada a uma combinação de fatores histogenéticos, histológicos e comportamento biológico. Corroborando com estas informações, Zachary (2018) cita que as neoplasias podem ser oriundas de alterações genéticas hereditárias e se farão presentes em todas as células do organismo, ou podem originar-se de alterações somáticas que são acumuladas nas células e tecidos individuais do corpo, ao longo do tempo, podendo ser decorrentes de causas químicas, físicas (radiação) ou infecciosas.

Os tumores indiferenciados têm aspecto microscópico, acentuadamente divergente das células que o originaram e, segundo Zachary (2018), podem conter arranjos celulares em ninhos, cordões e/ou ilhas de células epiteliais, pois são tumores malignos de origem epitelial, invasivos e possuem elevado potencial metastático. Carvalho et al. (2014) e Ramos et al. (2008), em pesquisas de neoplasias em bovinos na região sul do Rio Grande do Sul, verificaram frequência de 
3,7 e 2,22\%, respectivamente. Já em estudo realizado por Lucena et al. (2011), na região central do estado, a frequência de neoplasmas em bovinos foi maior que o dobro.

Martz et al. (2020) citam a ocorrência anual entre 0,003 a $0,250 \%$ para tumores no trato genital bovino, sendo que fibropapilomas e carcinomas de células escamosas ocorrem mais comumente na vulva, e tumores do músculo liso são mais comuns na vagina. Reis et al. (2017) verificaram maior prevalência de linfoma e carcinoma de células escamosas, em bovinos adultos, fêmeas, da raça Holandesa, nos sistemas hematopoiético, tegumentar e reprodutor feminino, respectivamente.

O carcinoma é uma patologia de importância no aspecto econômico, causando ao produtor grandes prejuízos, como o baixo desempenho animal, alto custo com tratamentos e, dependendo do prognóstico, o animal é submetido à eutanásia. Tendo em vista a escassa informação a respeito da ocorrência de distúrbios neoplásicos em bovinos na região do Alto Uruguai Gaúcho, este trabalho teve por objetivo relatar os achados de necropsia e histopatológicos de uma vaca holandesa em lactação, no município de Campinas do Sul - Rio Grande do Sul.

\section{Material e Métodos}

\section{Relato de Caso}

A metodologia empregada para a elaboração deste trabalho foi a avaliação do estudo de caso envolvendo uma vaca da raça Holandesa Preto e Branco (HPB), com 7 anos de idade e 200 dias de lactação. A propriedade contava com 100 animais em lactação, todos com as vacinas preventivas para leptospirose, rinotraqueíte infecciosa bovina (IBR), diarreia viral bovina (DVB), em dia.

$\mathrm{O}$ animal foi encaminhado para atendimento veterinário e, durante a anamnese, $\mathrm{o}$ proprietário relatou que a vaca possuía mastite crônica, retorno ao cio e aumento de volume na região da vulva. Com a autorização do proprietário, realizou-se o procedimento cirúrgico para retirada da massa vulvar, não sendo coletado material para exame histopatológico. Após seis meses, o animal apresentou aumento dos linfonodos mamários, apatia e emagrecimento progressivo. Na ausência de resposta clínica ao tratamento para mastite, e recidiva da tumoração na região da vulva, o proprietário solicitou a eutanásia do animal e necropsia para realização de diagnóstico definitivo.

A eutanásia seguiu conforme descrito no Código de Ética do Médico Veterinário, resolução $\mathrm{n}^{\circ} 1138$, de 16 de dezembro de 2016, que de acordo com o item XIII - realizar a eutanásia nos casos devidamente justificados, observando princípios básicos de saúde pública, legislação de proteção aos animais e normas do Conselho Federal de Medicina Veterinária (BRASIL, 2016).

A necropsia consiste na abertura e inspeção detalhada dos órgãos e tecidos de um cadáver, objetivando diagnosticar a causa da morte ou verificar a extensão e a natureza das lesões (RUBIO; JÍMENEZ, 2020). No caso descrito, foi utilizada a técnica de necropsia convencional, iniciando com o exame externo do cadáver para observação de alterações cadavéricas, bem como avaliação do estado nutricional. Na sequência foi realizada a abertura propriamente dita do cadáver, posicionando o animal em decúbito dorsal, com exposição da região ventral. Em seguida fez-se uma incisão longitudinal ao longo da linha mediana, da sínfise pubiana até a região mandibular (ANDRADE et al., 2002) para avaliação das alterações internas e possíveis neoplasias.

A partir da necropsia e visualização de alteração morfológica dos órgãos como a glândula mamária, dos linfonodos mamário, retrofaríngeo, mediastínico e ilíaco e 
dos rins, foram coletados fragmentos para análise histopatológica. Estas amostras foram fixadas em formol tamponado a $10 \%$, por 24 a 48h, para análise histopatológica, que consiste no corte dos fragmentos de $3 \mathrm{~mm}$, processamento em histotécnico (passagem em diferentes concentrações de álcool para desidratação do tecido, após em xilol para impregnação da parafina), confecção dos blocos de parafina para serem cortados em 3 $\mu \mathrm{m}$ em micrótomo e fixação dos tecidos em lâmina de vidro para serem corados pela técnica de hematoxilina e eosina (MINGOTTI et al., 2018). As amostras foram analisadas pelo Centro de Diagnóstico e Pesquisa em Patologia Veterinária do Instituto Federal Catarinense, Câmpus Concórdia/SC. O diagnóstico definitivo para carcinoma indiferenciado metastático foi obtido através da necropsia pela visualização macroscópica dos órgãos acometidos e realização do exame histopatológico.

\section{Resultados e Discussão}

Durante a avaliação clínica do animal, observou-se edema da glândula mamária, linfonodos mamários intumescidos, tumoração na região vulvar (Figura 1) e caquexia. Pela técnica de palpação retal, detectaram nódulos firmes na região do linfonodo ilíaco de aproximadamente 10 a $20 \mathrm{~cm}$. Devido ao prognóstico desfavorável, foi indicada a eutanásia do animal para posterior avaliação e diagnóstico através da necropsia e análise histopatológica.

Rosa et al. (2012) relatam que o desenvolvimento tumoral na região vulvar e assoalho vaginal é descrito em vacas, ovelhas e cabras que vivem em áreas onde há exposição solar prolongada. $\mathrm{O}$ animal do referido estudo era mantido em campo com pastagem exposto ao clima. Esses achados também corroboram com os estudos de Reis et al. (2017), que citam a maior incidência de neoplasmas em bovinos adultos, fêmeas, da raça Holandesa, sendo este geralmente o motivo de seu óbito. A maior suscetibilidade da raça Holandesa e suas cruzas pode ocorrer por possuírem áreas de pele clara ou hipopigmentada. Para Tsujita e Plummer (2010) o desenvolvimento da neoplasia pode estar relacionado à exposição prolongada de raios ultravioleta em pele despigmentada, sem pelos e com lesões prévias.

Relatos de casos semelhantes aos encontrados no presente estudo são citados por Borges (2019), que descreve um caso de tumor vulvar de uma vaca da raça girolando, com aspecto erosivo e presença de úlceras superficiais que se uniam por todo lábio vulvar direito. Saleme et al. (2015) relatam que um bovino, fêmea da raça nelore, com histórico de aumento de volume em região vulvar, apresentou carcinoma vulvar de células escamosas.

Figura 1 - Aspecto da tumoração na região vulvar de uma vaca da raça Holandesa Preta e Branca de 7 anos de idade, após recidiva, seis meses após a ressecção cirúrgica

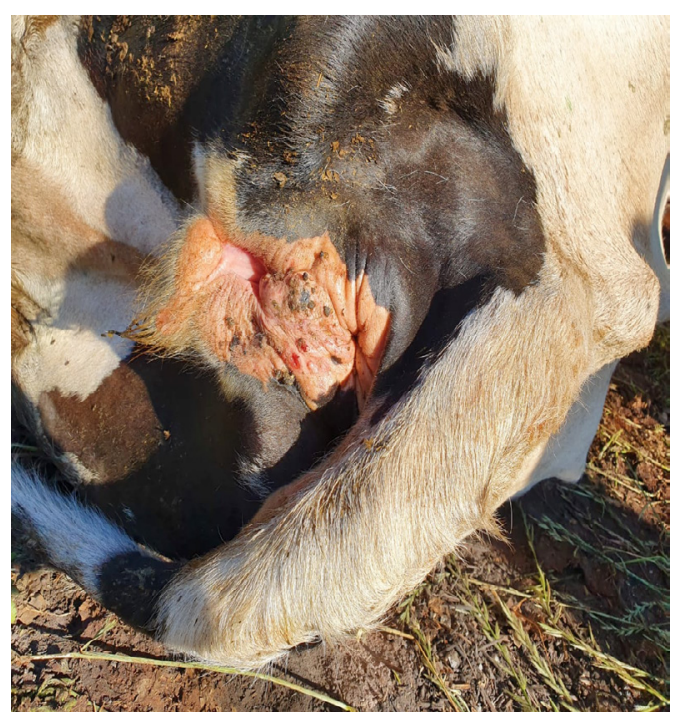

Os fragmentos coletados após eutanásia do referido animal, apresentaram, na glândula mamária, nódulos de aproximadamente 10x8 
cm de diâmetro. A Figura 2 (a) demonstra fragmentos da glândula mamária e linfonodo mamário e, a Figura 2 (b), linfonodos mediastínicos aumentados de tamanho, firmes e amarelados. Ao corte, apresentaram coloração interna branco-amarelada com pontos multifocais amarelo-ouro. De acordo com Aluja e Casas (2002) a identificação e descrição morfológica das alterações realizadas na necropsia servem para poder evidenciar enfermidades e, através disso, identificar o agente causador da doença.

Figura 2 - Fragmentos da glândula mamária com linfonodo mamário (a) e linfonodo mediastínico (b) de uma vaca da raça Holandesa Preta e Branca de 7 anos de idade.

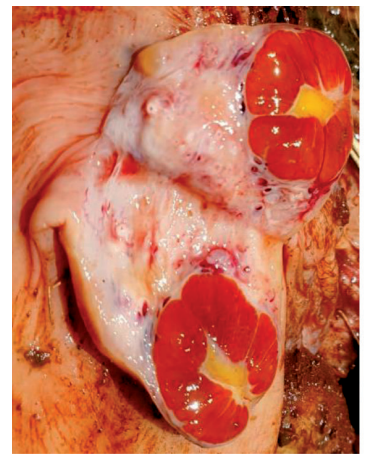

(a)

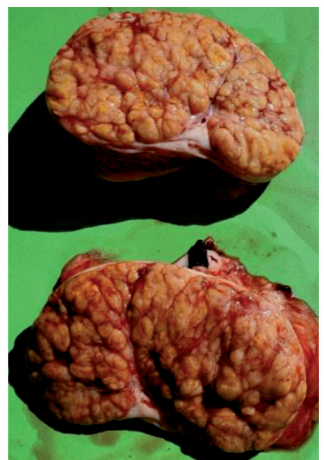

(b)
Piva et al. (2017), durante a realização da necropsia de um bovino fêmea, observaram que a glândula mamária estava severamente aumentada e apresentava uma fístula drenando quantidade moderada de exsudato supurativo à direita, no quarto traseiro. No presente relato de caso, a superfície cortada dos quartos das glândulas revelou múltiplos nódulos, variando de 5 a $20 \mathrm{~cm}$, disseminados no parênquima do úbere. Os nódulos maiores apresentaram áreas amolecidas no centro. Metástases foram observadas nos linfonodos mamários, rins, baço, fígado, pâncreas, linfonodos mediastinos, coração e pulmões. Esses órgãos foram ampliados e apresentavam nódulos multifocais, firmes, brancos a amarelados, que variaram muito em tamanho.
Barbosa et al. (2018) observaram aumento de volume da glândula mamária, com consistência firme ao corte e perda da arquitetura normal, com liberação de conteúdo viscoso, róseo e fétido. No presente relato de caso, os linfonodos mamários estavam aumentados de volume e, ao corte, verificaram-se lesões multifocais ou coalescentes, com perda da delimitação corticomedular e liberação de conteúdo viscoso semelhante ao encontrado na glândula mamária.

Nos resultados histopatológicos de linfonodos e glândula mamária do presente relato (Figura 2), verificou-se a proliferação de células epiteliais de núcleo arredondado com 20 a $30 \mu \mathrm{m}$ de cromatina parcialmente condensada e nucléolo evidente. Foi constatado, também, alta atipia celular, sete mitoses por campo de maior aumento $\left(0,237 \mathrm{~mm}^{2}\right)$. Constava um arranjo sólido que, por vezes, formava ninhos, com crescimento infiltrativo não encapsulado, e ainda, um infiltrado inflamatório linfoplasmocitário moderado multifocal.

Resultados semelhantes foram encontrados por Piva et al. (2017), evidenciando a proliferação neoplásica maligna e infiltrativa do epitélio celular, caracterizada por uma massa não delimitada e mal encapsulada, organizada em túbulos e papilas com quantidade moderada de estroma conjuntivo. As células apresentaram abundante citoplasma eosinofílico, núcleos arredondados a ovais, variando de 3 a $5 \mu \mathrm{m}$, com alterações intensas de forma e atípica mitose. Nucléolos grandes, proeminentes, geralmente únicos e com presença de cromatina granular. Já, Barbosa et al. (2018), observaram proliferação de ductos neoplásicos revestidos por numerosas células neoplásicas, apresentando pleomorfismo que variava de moderado a acentuado, com moderada anisocitose e anisocariose. Os linfonodos estavam com arquitetura alterada por infiltração neoplásica maligna semelhante à descrita na glândula mamária. Ohfuji (2012), 
descreve um caso de carcinoma secretório mamário em vaca, onde a massa neoplásica demonstrou-se altamente agressiva e maligna e as células neoplásicas exibiram imunorreatividade da citoqueratina, indicando a origem epitelial.

Embora tenha sido relatado, neste estudo, um caso de carcinoma em uma vaca da raça Holandesa Preta e Branca, sabe-se que em bovinos esta ocorrência é pouco frequente e, segundo Mihevc et al. (2013), esta baixa incidência pode estar relacionada a gestações consecutivas, ineficiência do ciclo de estrogênio durante a parição, descarte precoce e produção de leite elevada. Barbosa et al. (2018) também afirmam que tumores mamários raramente ocorrem em animais de produção, sendo as neoplasias de glândula mamária mais predominantes em cadelas e gatas.

Mesmo com poucos relatos e estudos sobre neoplasias em bovinos, Ramos et al. (2008), durante o período de 1978 a 2002, constataram 98 casos, sendo a maioria dos tumores de origem hematopoiética (todos linfomas). Outros tumores de relevância foram encontrados, sendo a maioria deles classificados como carcinoma de células escamosas (CCE) - tumor epitelial (em diferentes regiões, inclusive vulvar) e os fibromas - origem mesenquimal. Em alguns casos havia somente metástases de carcinomas de células escamosas localizadas em linfonodos parotídeos, submandibulares e retrofaríngeos.

Na necropsia também se observou que na superfície dos rins (Figura 3) havia múltiplas áreas avermelhadas inferiores a $0,2 \mathrm{~cm}$ de diâmetro. No exame microscópico do rim observou-se glomerulonefrite proliferativa, visto que nos glomérulos havia a proliferação de células mesangiais moderado difuso. Semelhantes resultados foram observados por Piva et al. (2017), que relataram que os rins foram os órgãos mais severamente afe- tados. Em seus estudos os rins apresentaram nódulos multifocais variando de 0,1 a 12 cm na superfície do órgão e parênquima. Já, no caso em estudo, a maior parte das lesões encontradas nesse órgão caracterizaram-se pela formação de petéquias.

Figura 3 - Rim de uma vaca da raça Holandesa Preta e Branca, de 7 anos de idade, apresentando diversas petéquias

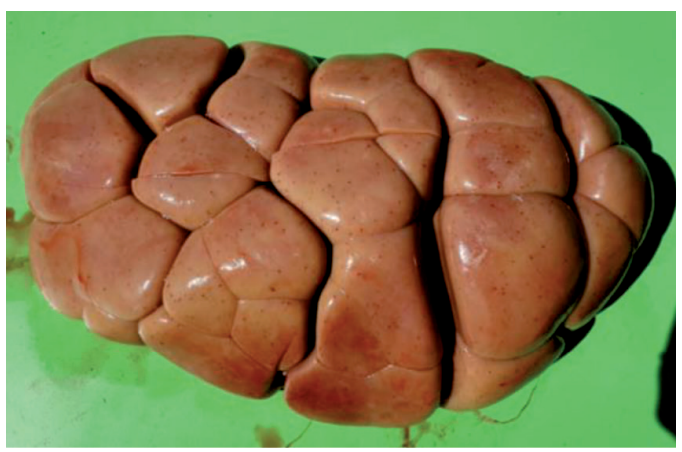

Lucena et al. (2011) citam a ocorrência de carcinoma em células renais de bovinos e em seus achados a maioria dos animais eram adultos e apresentavam, principalmente, perda de peso, seguido de surgimento de massas abdominais palpáveis, tosse, hiporexia, anorexia, dor abdominal e febre com menor incidência. Isto tudo corrobora com os achados em questão, onde o animal apresentou aumento dos linfonodos mamários e nas proximidades com o ilíaco, aumento da região vulvar, apatia e emagrecimento progressivo.

A partir dos achados de necropsia e análise histopatológica, o diagnóstico foi carcinoma indiferenciado metastático. Segundo Mendes et al. (2016), as características principais dos carcinomas indiferenciados são laminações altamente aglomeradas em volta de células poliédricas, fazendo com que não seja possível diferir as características de adenocarcinomas mais diferenciados, podendo apresentar ainda, algum grau de atipia celular e pleomorismo e mitoses são regularmente frequentes. 
O diagnóstico definitivo geralmente pode ser alcançado através de exame macroscópico e histopatológico. Contudo, casos como o relatado aqui, onde muitos órgãos são afetados por metástases, análise imuno-histoquímica pode ser necessária para estabelecer as principais origens do tumor.

\section{Conclusão}

As neoplasias são importantes causas de descarte precoce de bovinos leiteiros, devido às alterações que causam em diversos siste- mas do organismo, sendo um dos principais efeitos colaterais o emagrecimento acelerado dos animais, ocasionando queda na produção leiteira, com significativos prejuízos ao produtor, além de possuírem prognóstico desfavorável no casos dos carcinomas indiferenciados. Portanto, é imprescindível o acompanhamento veterinário constante dos rebanhos nas propriedades, para prevenir enfermidades, facilitando o diagnóstico precoce e o tratamento dos animais, aumentando a sobrevida e diminuindo as perdas nas propriedades.

\section{REFERÊNCIAS}

ALUJA, A. S.; CASAS, F. C. Técnicas de necropsia em animales domésticos. D. R.C2002 ISBN 968-426-938-2. Editorial El Manual Moderno.

ANDRADE, A.; PINTO, S. C.; OLIVEIRA, R. S.; Animais de Laboratório: criação e experimentação. In: CARDOSO, C. V. P. Capítulo: Técnica de Necropsia. Rio de Janeiro: Editora FIOCRUZ, 2002. 388 p. Disponível em: http://books.scielo.org/id/sfwtj.

BARBOSA, F. M. S.; DANTAS, S. V. S.; NASCIMENTO, H. H. L.; ARAÚJO SOBRINHO, J. P.; SANTOS, J. R. S.; KOMMERS, G. D.; LUCENA, R. B. Carcinoma mamário ductal invasivo em uma vaca. Acta Scientiae Veterinariae, v. 46, n.1, p. 288, 2018. Disponível em: https://pesquisa. bvsalud.org/portal/resource/pt/vti-728678.

BORGES, P. P. Clínica, cirurgia e reprodução de bovinos. In: Carcinoma de células escamosas em lábio vulvar bovino-relato de caso. 2019. 25 f. Relatório de estagio curricular supervisionado. (Trabalho de conclusão de curso em Medicina Veterinária) - Instituto Federal Goiano- Campus Urutaí, GO, 2019. Disponível em: https://repositorio.ifgoiano.edu.br/handle/prefix/1156.

BRASIL. Conselho Federal de Medicina Veterinária. Código de Ética do Médico Veterinário. Resolução No 1138, de 16 de Dezembro de 2016. Disponível em: http://www.crmv-ro.org.br/pdf/ imagens/11/codigo-etica-mv.pdf.

CARVALHO, F. K. L.; DANTAS, A. F. M.; RIET-CORREA, F.; ANDRADE, R. L. F. S.; NÓBREGA, P. I. N.; MIRANDA, E. G. N.; SIMÕES, S. V. D.; AZEVEDO, S. S. Estudo retrospectivo das neoplasias em ruminantes e equídeos no semiárido do Nordeste Brasileiro.

Pesquisa Veterinária Brasileira, v. 34, n. 3, p. 211-216, 2014. Disponível em: https://www.scielo. br/scielo.php?pid=S0100-736X2014000300003\&script=sci_abstract\&tlng=pt

CULLEN, J.M.; PAGE, R. ; MISDORP, W. An overview of cancer pathogenesis, diagnosis and management. In: MEUTEN, D.J. Tumors in domestic animals. 4. ed. Ames: Iowa State, Cap.1, p.03-44, 2002. E-book.

LUCENA, R. B.; RISSI, D. R.; KOMMERS, G. D., PIEREZAN, F.; OLIVEIRA-FILHO, J. C.; MACÊDO, J. T. S. A.; FLORES, M. M.; BARROS, C. S. L. A retrospective study of 586 tumours 
in Brazilian cattle. Journal of Comparative Pathology, v. 145, n.1, p. 20-24, 2011. Disponível em: https:/www.sciencedirect.com/science/article/pii/S0021997510003324?via\%3Dihub.

MARTZ, P.; OEZCAN-MARTZ, A.; BITTNER, L.; EBERT, F.; WIPPERMANN, W.; WOECKEL, A; BOETTCHER, D.; BAUMGARTNER, W.; STARKE, A. Case reports of genital tract tumours in cows. Veterinary Medicina, v. 09, n. 65, p. 401-408, 2020.

Disponível em: https://www.agriculturejournals.cz/publicFiles/124_2020-VETMED.pdf

MENDES, E. R.; STEDILLE, F. A.; POZZO, D. I.; BROLL, F. Casuística de neoplasias diagnosticadas em bovinos do Oeste de Santa Catarina - um estudo retrospectivo. Centro de Diagnóstico e Pesquisa em Patologia Veterinária, IFC - Concórdia, v.1, n.1, p. 11, 2016. Disponível em: https://publicacoes. ifc.edu.br/index.php/BoletimDiagnostico-IFC-Concordia/article/view/119.

MIHEVC, S.P.; DOVC, P. Mammary tumors in ruminants. Acta Agriculturae Slovenica. v. 102, n. 2 p. 83-86, 2013. Disponível em: https://www.researchgate.net/publication/259717467_Mammary_ tumors_in_ruminants/link/00b7d52d7992cd25ed000000/download.

MINGOTTI, T. R.; ALVES, F. D.; GRIS, A.; CECHIN, R. A.; PEROSA, F. F.; BAVARESCO, L. H.; WERLANG, R. A.; LIMA, J. L. F. DE.; GOMES, T. M. A.; CASAGRANDE, R. A., MENDES, R. E. Intoxicação por Pteridium arachnoideum no oeste de Santa Catarina: estudo retrospectivo (20132017). Centro de Diagnóstico e Pesquisa em Patologia Veterinária, IFC - Campus Concórdia, v. 2, n. 1, p. 7, 2018. Disponível em: https://publicacoes.ifc.edu.br/index.php/BoletimDiagnosticoIFC-Concordia/article/view/520.

OHFUJI, S. Case report. Secretory carcinoma of the mammary gland in an 8-year-old HolsteinFriesan dairy cow. Veterinary Quaterly, v. 32, n. 2, p. 113-115, 2012. Disponível em: https://www. tandfonline.com/doi/pdf/10.1080/01652176.2012.713165?needAccess=true

PIVA, M. M.; SCHWERTZ, C. I.; HENKER, L. C.; MILLÁN, Y.; MULAS, J. M.; STEDILLE, F. A.; CHRIST, R.; GABRIEL, M. E.; SILVA, T. M. A.; COUTO, C.; CASAGRANDE, R. A.; MEDEIROS, D. S.; MENDES, R. E. Metastatic mammary carcinoma in a cow. Ciência Rural, v. 47, n. 7 Santa Maria 2017. Disponível em: https://www.scielo.br/scielo.php?script=sci_arttext\&pid $=\mathrm{S} 0103-84782017000700551$

RAMOS, A.T.; SOUZA, A. B. DE; NORTE, D. M.; FERREIRA, J.L. M.; FERNANDES, C. G.; Tumores em animais de produção: aspectos comparativos. Ciência Rural, v. 38, n.1, p.148154, Santa Maria, 2008. Disponível em: https://www.scielo.br/scielo.php?script=sci_arttext\&pid $=\mathrm{S} 0103-84782008000100024$

REIS, M. O.; SLAVIERO, M.; LORENZETT, M. P.; CRUZ, R. A. S.; GUIMARÃES, L. L. B.; PAVARINI, S. P.; DRIEMEIER, D.; SONNE, L. Neoplasmas bovinos diagnosticados no Setor de Patologia Veterinária da UFRGS, Porto Alegre (2005-2014). Pesquisa Veterinária Brasileira, n. 37, v. 2, p. 105-109, 2017. Disponível em: https://www.scielo.br/pdf/pvb/v37n2/1678-5150pvb-37-02-00105.pdf.

ROSA, F.B.; KOMMERS, G.D.; LUCENA, R.B.; GALIZA, G.J.N.; TOCHETTO, C.; SILVA, T.M.; SILVEIRA, I.P. Aspectos epidemiológicos, clinicopatológicos e imunohistoquímios de carcinomas de células escamosas vulvares em 33 vacas. Pesquisa Veterinária Brasileira, v. 32, p.1127-1132, 2012. Disponível em: https://www.scielo.br/scielo.php?script=sci_arttext\&pid=S0100736X2012001100009.

RUBIO, V. G. G.; JIMÉNEZ, R. M. DE O. Manual de Prácticas Patología General. Universidad Autónoma del Estado de México Centro Universitario UAEM Amecameca Licenciatura en Medicina Veterinaria y Zootecnia. 68p. Disponível em: https://uaemex-cuameca.mx/images/doc/4P/PGMP.pdf. SALEME, J. C.; DE OLIVEIRA, S. M.; JUNQUEIRA, J. R. C.; GOIOZO, P. F. I.; DA SILVA, E. O. Carcinoma de células escamosas vulvar em bovino: Relato de caso. Colloquium Agrariae, v. 11, n. 
2, p. 54-59, 2016. Disponível em: https://revistas.unoeste.br/index.php/ca/article/view/1360. Acesso em: 12 abr. 2021.

TESSELE, B.; BARROS, C. S. L. Tumores em bovinos encontrados em abatedouros frigoríficos. Pesquisa Veterinária Brasileira, v. 36, n. 3, p. 145-160, março 2016. Disponível em: https://www. scielo.br/pdf/pvb/v36n3/1678-5150-pvb-36-03-00145.pdf.

TSUJITA H.; PLUMMER C.E. Bovine ocular squamous cell carcinoma. Veterinary Clinics Food Animal, 26, p.511-529, 2010

ZACHARY, J. F. Bases da Patologia em Veterinária. In: NEWKIRK, K. M.; BRANNICK, E. M.; KUSEWITT D. F. Neoplasia e Biologia Tumoral. 6. ed. Rio de Janeiro: Elsevier, 2018, p. 286-319. E-book. 
